\title{
LDG: Lateral Design Graph
}

\section{Schierle GG*}

USC, School of Architecture Los Angeles, CA, USA

"Corresponding author: Schierle GG, USC, School of Architecture, Los Angeles, CA, USA, Tel: +213-740-4590; Fax: +213-740-8884; E-mail: Schierle@usc.edu

Received date: October 10, 2016; Accepted date: October 12, 2016; Published date: October 30, 2016

Citation: Schierle GG (2016) LDG: Lateral Design Graph. J Steel Struct Constr 2: e108. doi:10.4172/2472-0437.1000e108

Copyright: ( 2016 Schierle GG. This is an open-access article distributed under the terms of the Creative Commons Attribution License, which permits unrestricted use, distribution, and reproduction in any medium, provided the original author and source are credited.

\section{Lateral Design Graph}

LDG is an Excel macro to design for lateral wind and seismic loads based on ASCE 7 and the IBC (International Building Code). The objective of LDG is to provide numerical tables and optional graphs to visualize lateral design data. The graphs reinforce important informed intuition regarding force, shear and overturn moment distribution. LDG requests user input of building size as well as wind and seismic data. Building data includes $\mathrm{x}$-width, $\mathrm{y}$-length, number of stories, story heights, and dead load. The data may be equal or variable for all stories. LDG also requests wind and seismic importance factors, wind speed, exposure- and gust-factors, etc. for wind design, R-factors, Sfactors, etc. for seismic design. For clarity, seismic data is beige and wind data green. Based on the user input LDG provides numeric table and optional graphs defining for each level lateral force, shear and overturn moment. For wind load LDG provides data in both X- and Ydirections. The graphs may be displayed on the Excel input screen or on a separate Excel screen. The attached screen includes seismic force Fs, shear Vs, overturn moment Ms and wind graphs in X-direction, force Fwx shear Vwx and overturn moment Mwx. The first column of the wind table provides the wind pressure in psf. LDG includes a separate tutorial to introduce the LDG features and use (Figures 1 and 2).

LDG is posted under Arch 499 at: http://uscarch.com/

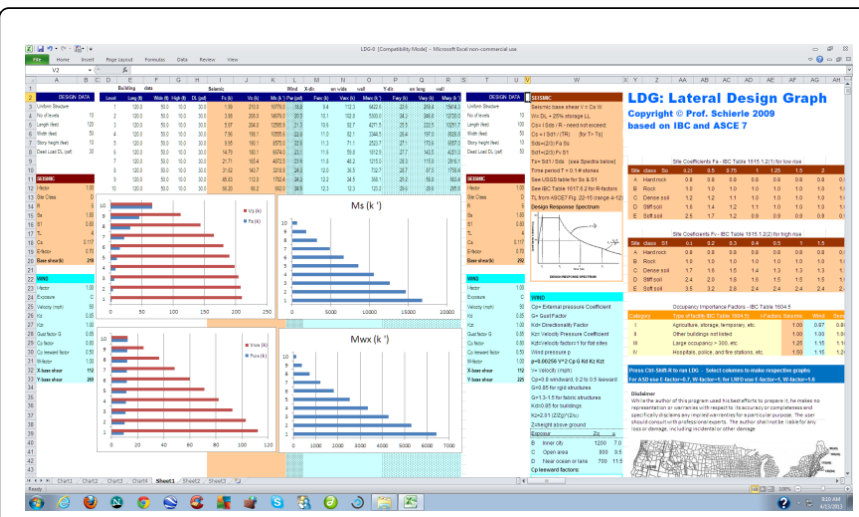

Figure 1: LDG screen of 10-story building: $50 \times 120$ feet. 